\title{
Carboxylated Magnetite Composite Polymer Nanoparticles with Mosaic Structure for Biomedical Application
}

\author{
Kesavarao Sykam and Shailaja Donempudi
}

Polymers \& Functional Materials Division, Indian Institute of Chemical Technology, Hyderabad 500007, India

\begin{abstract}
In this article, a microemulsion method for preparation of magnetite composite polymer nanoparticles of $\mathrm{Fe}_{3} \mathrm{O}_{4} @$ poly(styrene-methacrylic acid) (MNP@PSMA) crosslinked with1,6-hexanediol diacrylate (HDD) insitu with carboxyl functionality on the surface has been reported. Structure and morphology of the nanoparticles was studied by Fourier Transform Infrared spctroscopy (FTIR), X ray Diffraction (XRD), Thermal Gravimetric Analyser (TGA), Vibrating Sample Magnetometer (VSM) and Transmission Electron Microscopy (TEM). VSM studies confirmed saturation magnetization of $20.0 \mathrm{emu} / \mathrm{g}$ in an external magnetic field. Nanoparticles formed were of $30 \mathrm{~nm}$ in diameter with narrow size distribution and mosaic structure providing a large surface area useful for application in bioseparation. Experimental results of covalent coupling of composite nanoparticles indicated maximum protein binding capacity of 350 mg bovine serum albumin $(B S A)$ per gram.
\end{abstract}

Keywords: Microemulsion, magnetic nanoparticle supports, protein separation.

\section{INTRODUCTION}

Polymer supported magnetic nanoparticles have gained prominence owing to their potential applications in many fields like, biology [1], catalysis [2,3], waste water treatment [4,5], biomedicine [6] and magnetic resonance image like contrast agent in MRI application [7]. Lee at al, reported that magnetic nanoparticles act as negative $T_{2}$ contrast agents in MRI [8]. Schmieder et al., used 2-4 $\mathrm{nm}$ sized magnetic nanoparticles to detect very small area of angiogenesis [9]. In biomedicine, separation of specific biological entities from the native environment is often performed to obtain concentrated samples for subsequent analysis. This is generally performed in two steps where these entities are first tagged to magnetic nanoparticles followed by separation in the presence of an external magnetic field depending on their magnetophoretic mobility. Tagging or labeling is done by chemical modification of the magnetic nanoparticles with polymer supports which not only offer colloidal stability to the magnetic fluids but also provide functionality for coupling with biological entities such as genes, virus, proteins or cells for bio separation. Surface modification of magnetic nanoparticles (MNP's) by organic moieties was possible with synthetic polymer coatings such as poly (vinyl alcohol) [10], poly (vinyl chloride) [11], poly (methyl methacrylate) [12], poly (methyl acrylate) [13], and poly (ethylene oxide) [14]. Reports on using natural polymers like starch [15, 16], and carboxymethyl dextran [17], surfactant coatings [18, 19] and molecular grafting by silica based organic moieties [20-22] or other inorganic materials is also known [23-25]. Factors

*Address correspondence to this author at the Polymers \& Functional Materials Division, Indian Institute of Chemical Technology, Hyderabad 500007, India; E-mail: sdonempudi@iict.res.in

E-ISSN: 1929-5995/15 essential for effective functioning of magnetic nanoparticles are nano size comparable or smaller than the entity and non-porous nature that renders them with larger surface area and faster adsorption kinetics. However, it is rather difficult to make polymer supported magnetic nanoparticles of the range $5-50 \mathrm{~nm}$ that can exhibit optimum magnetic susceptibility and simultaneously offer high binding capacity. Limitation on size range of the nanoparticles makes it difficult to accommodate both magnetite as well as functional groups ligands. Such a problem can be overcome by proper design and decoration of MNP's on the polymer supports that can accommodate enough functional groups for efficient coupling of affinity ligands. However, choice of an appropriate polymer and synthetic method may result in supports with desired size $(5-50 \mathrm{~nm})$ suitable for effective protein binding and separation.

In the present study, micro-emulsion polymerization method was followed to prepare in situ paramagnetic MNP's functionalized composite nanoparticles of HDD crosslinked PSMA copolymer (MNP@PSMA) where carboxylic groups of MAA are deposited exclusively on the surface due to its higher affinity to aqueous medium. Coupling strategy for MNP@PSMA with bovine serum albumin (BSA) protein to form BSA@MNP@PSMA nanoparticles has been reported. All the steps for modification of nanoparticles at every stage were characterized and confirmed by FTIR, powder XRD, TGA and VSM.

\section{EXPERIMENTAL}

\section{Materials}

Styrene (St), 1,6-hexanediol diacrylate (1,6-HDDA), Methacrylic acid (MAA), Sodium dodecyl Sulphate

(C) 2015 Lifescience Global 
(SDS), 3-(Methacryloxysilyl) propyl methacrylate.98\% (MPS), were purchased from Sigma Aldrich. Potassium peroxodisulphate (KPS) was purchased from FLUKA chemicals. Iron (II) Chloride tetrahydrate (98\%) from Alfa Aesar. Iron (III) chloride hexahydrate $\left(\mathrm{FeCl}_{3} \cdot 6 \mathrm{H}_{2} \mathrm{O}\right)$, Benzoyl peroxide (BPO) LR were recrystallized from water ammonia solution Sp.gr. about $25 \%$ extra pure, Albumin Bovine Fraction $\mathrm{V}$ powder (BSA) and Tween 20 were procured from S.D. Fine Chemicals, Mumbai. 1- (3-Di methylamino propyl) 3-ethylcarbodimide hydrochloride $(\mathrm{EDC}-\mathrm{HCl})$ from Spectrochem. $0.1 \mathrm{~N} \mathrm{HCl}$ solution and buffer solutions of $\mathrm{pH} 4.5$ and $\mathrm{pH} 7.5$ were made in the laboratory using $\mathrm{pH}$ tablets supplied by SD Fine Chemicals.

\section{Preparation of $\mathrm{Fe}_{3} \mathrm{O}_{4}$ Nanoparticles (MNP's)}

In a three necked round bottom flask, $\mathrm{FeCl}_{2} \cdot 4 \mathrm{H}_{2} \mathrm{O}$ $(1.72 \mathrm{~g})$ and $\mathrm{FeCl}_{3} \cdot 6 \mathrm{H}_{2} \mathrm{O}(4.72 \mathrm{~g})$ were dissolved in $80 \mathrm{ml}$ of deionized water with vigorous stirring at $800 \mathrm{rpm}$ under nitrogen atmosphere. As the temperature was elevated to $80{ }^{\circ} \mathrm{C}, 10 \mathrm{ml}$ of Ammonium hydroxide was added drop wise and the reaction was maintained for 30 min. Black colour $\mathrm{Fe}_{3} \mathrm{O}_{4}$ nano particles (MNP) were obtained and separated in the presence of external magnetic field.

\section{Preparation of Surface Modified MNP's (MNP-MPS)}

In a $50 \mathrm{ml}$ round bottom flask $\mathrm{Fe}_{3} \mathrm{O}_{4}$ nanoparticles $(0.3 \mathrm{~g})$ were taken with $15 \mathrm{ml}$ methanol and $4 \mathrm{ml}$ deionized water. To the above mixture $0.5 \mathrm{ml}$ of $1 \mathrm{~N}$ Hydrochloric acid was added to adjust $\mathrm{pH}$ to 2 and was sonicated for 1 hour. Later, MPS was added while the oil bath temperature was raised to $70{ }^{\circ} \mathrm{C}$ and stirring was continued for 5 hours. Finally the surface modified $\mathrm{Fe}_{3} \mathrm{O}_{4}$ particles with MPS were isolated by filtration and washed with methanol and water.

\section{Preparation of MNP@PSMA Nanoparticles}

In a $500 \mathrm{ml}$ round bottomed flask, the surface modified magnetite nanoparticles (MNP-MPS), Styrene, 1, 6-hexanediol diacrylate and Benzoyl

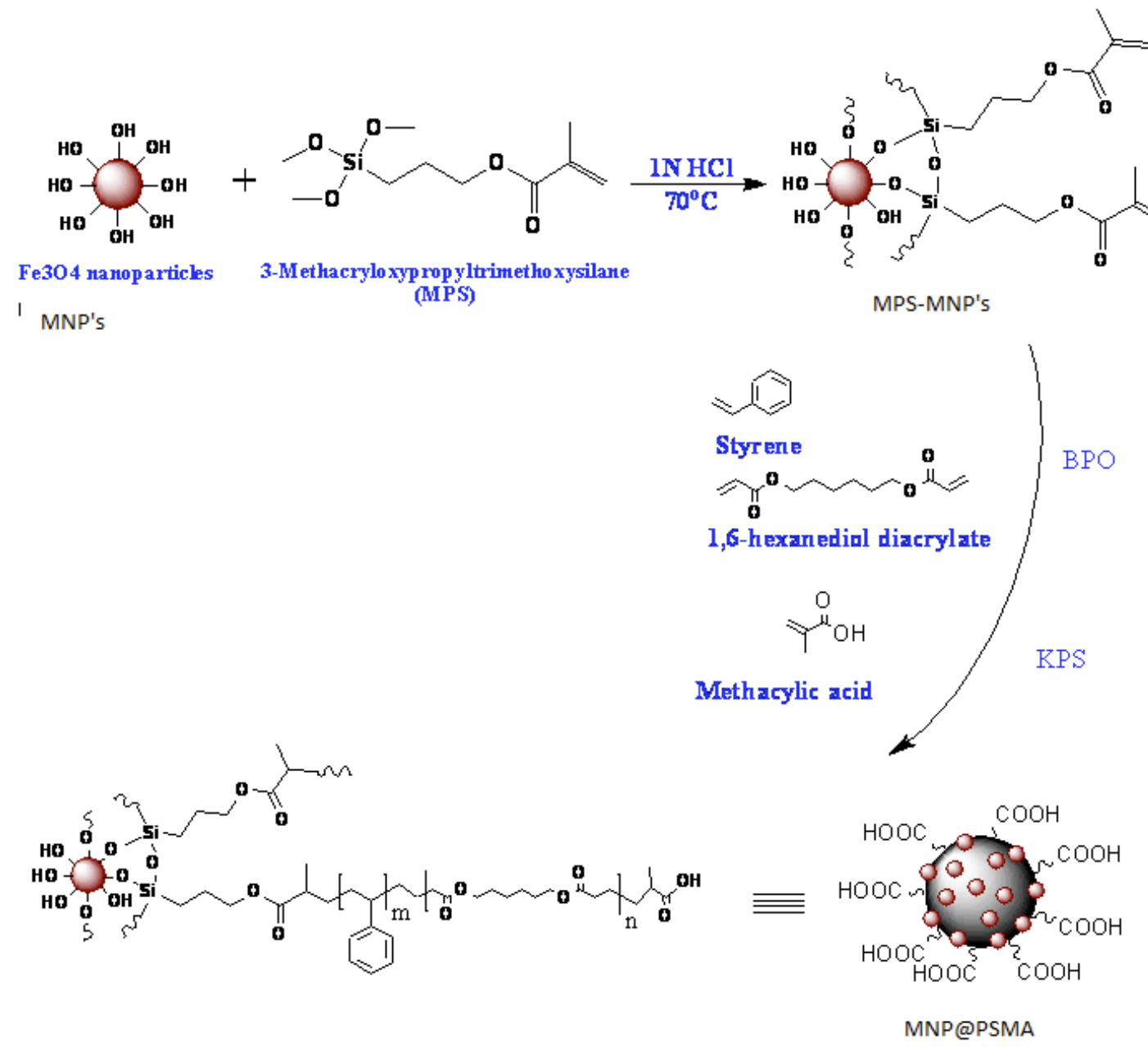

Scheme 1: Schematic illustration of synthesis of MNP@PSMA nanoparticles. 
peroxide were taken with $80 \mathrm{ml}$ of SDS solution. $\mathrm{pH}$ of the reaction mixture was adjusted to $9-11$ by addition of $1 \mathrm{M} \mathrm{NaOH}$ solution. The above reaction mixture was stirred for 2 hours at $1000 \mathrm{rpm}$ in order to get a preemulsion. Reaction temperature was then raised to $90^{\circ} \mathrm{C}$. After 40 minutes, a mixture of Methacrylic acid (MAA) and Potassium peroxodisulfate (PPS) in $20 \mathrm{ml}$ deionized water was added drop wise. After 3 hours of reaction a brown coloured emulsion was obtained which was stored in the refrigerator. Schematic representation of the synthetic procedure for MNP@PSMA nanoparticles is shown in Scheme 1.

\section{Coupling of BSA with MNP@PSMA Nanoparticles}

About $250 \mathrm{mg}$ of MNP-PSMA polybeads were added to $30 \mathrm{ml}$ potassium hydrogen phthalate buffer solution ( $\mathrm{pH} 4.5)$ and vortex mixed. The solution of 125 mg BSA with $10 \mathrm{ml}$ freshly prepared EDC solution $(10 \mathrm{mg} / \mathrm{ml})$ was added to MNP@PSMA nanoparticles. After vortex mixing the mixture was shaded from light and was shaken over night at room temperature in shaker water bath (model: JULABO SW 22, Germany). Later, $10 \mathrm{ml}$ of $10 \%$ tween 20 was added to it, vortex mixed and centrifuged for $30 \mathrm{~min}$. After removing the supernatant $50 \mathrm{ml}$ of $0.1 \%$ SDS was added and once again vortex mixed, centrifuged for $30 \mathrm{~min}$ and supernatant was removed. Finally the BSA coupled polymer supports were re-suspended in $\mathrm{pH} 7.5$ buffer solution and again vortex mixed, centrifuged and separated from the supernatant. The final residue obtained happens to be coupled BSA@MNP@PSMA nanoparticles which were collected and stored in refrigerator. The coupling strategy between MNPPSMA and BSA is shown in Scheme 2.

\section{Estimation of Surface Carboxylic Acid Groups on MNP@PSMA and BSA@MNP@PSMA Nanoparticles}

In an Erlenmeyer flask 0.1g of dry MNP@PSMA was taken in $100 \mathrm{ml}$ of isopropyl alcohol. To the above mixture a few drops of the phenolphthalein indicator was added. The above mixture was stirred and titrated with $0.5 \mathrm{~N}$ methanolic potassium hydroxide until pink coloured end point appears [26]. The titrant value was noted and substituted in the below equation in order to calculate surface carboxylic acids as a function of number of moles of potassium hydroxide necessary to neutralize acids in 1 gram of sample.

$$
\begin{aligned}
& \text { Acid value, } \mathrm{mg} \mathrm{KOH} / \mathrm{gram}=\frac{(\mathrm{M} . \mathrm{Wt} \text { of } \mathrm{KOH})(\text { Volume of } \mathrm{KOH} \text { consumed })(\text { Normality of } \mathrm{KOH})}{\text { Wt of polymer taken }} \\
& \text { Acidity, meq/gram }=\frac{(\text { volume of } \mathrm{KOH} \text { consumed })(\text { Normality of } \mathrm{KOH})}{\text { Wt of polymer taken }}
\end{aligned}
$$

\section{RESULTS AND DISCUSSIONS}

The FT-IR spectra of MNP's and their surface modification, incorporation into polymer and coupling with protein, all these steps are shown in Figure 1. The absorption band at $582.9 \mathrm{~cm}^{-1}$ is assigned to the stretching vibration of $\mathrm{Fe}-\mathrm{O}$ band of $\mathrm{Fe}_{3} \mathrm{O}_{4}$ and the broad band at $3411 \mathrm{~cm}^{-1}$ corresponds to stretching vibration of surface water molecule or the envelope of hydrogen bonded surface hydroxyl groups. Compared with bare MNP's and surface modified $\mathrm{Fe}_{3} \mathrm{O}_{4}$ (MNPMPS) show two new absorption bands at $1630 \mathrm{~cm}^{-1}$

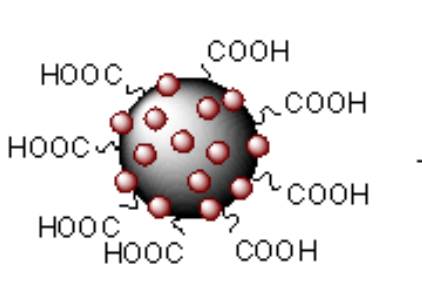

MNP@PSMA

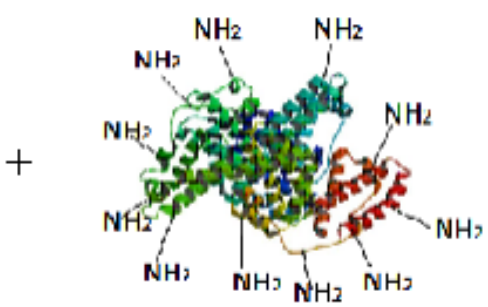

BSA

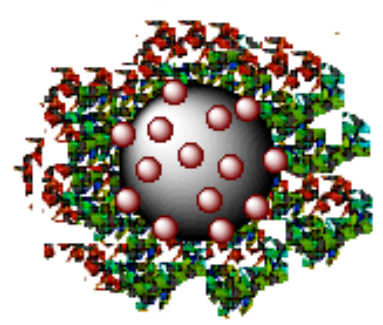

BSA@MNP@PSMA

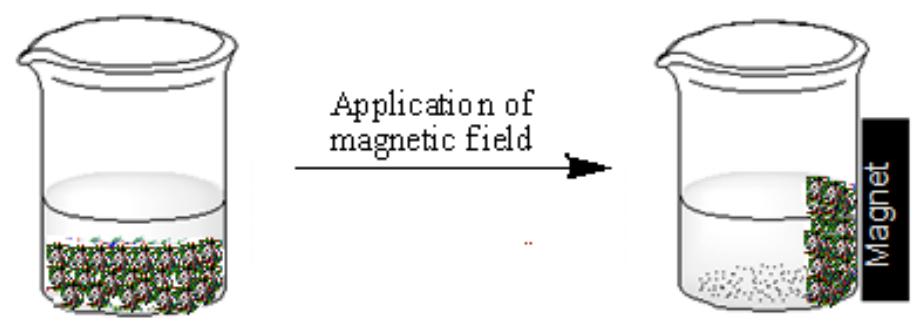

Scheme 2: Schematic representation of coupling strategy between MNP@PSMA nanoparticles and BSA. 


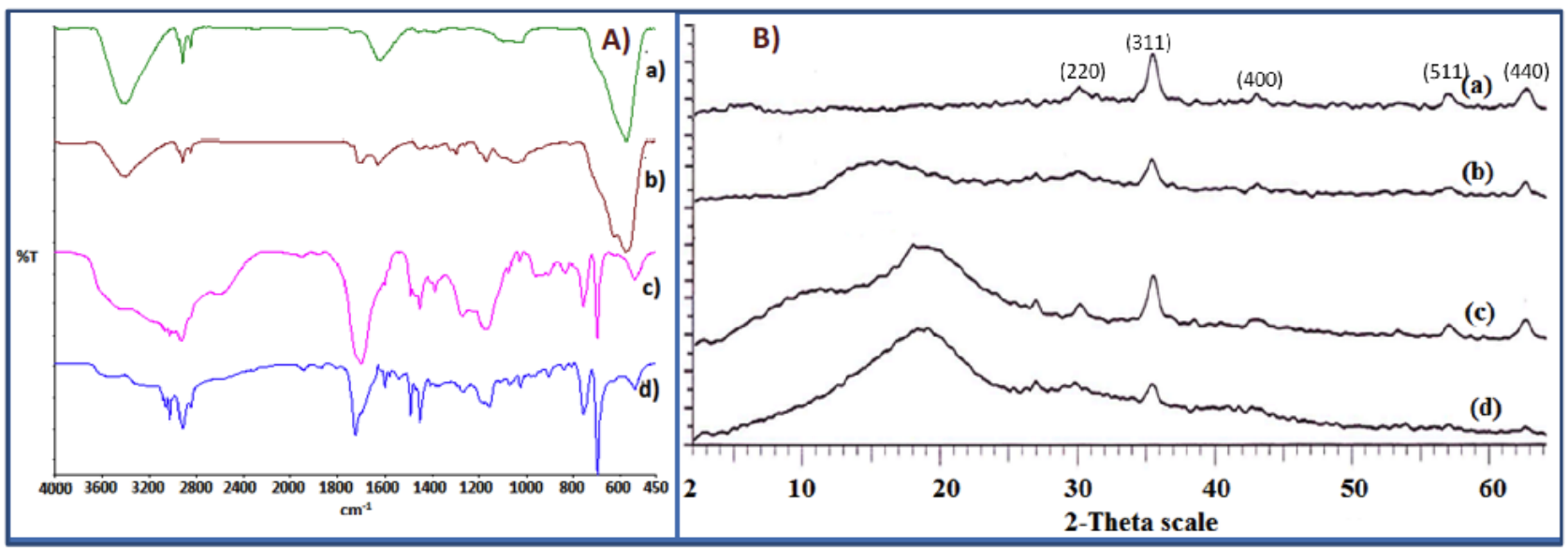

Figure 1: A) FT-IR overlay of a) MNPs b) MNP-MPS c) MNP@PSMA d) BSA@MNP@PSMA and B) XRD overlay of a) MNP's b) MNP-MPS c) MNP@PSMA d) BSA@MNP@PSMA.

and $1706 \mathrm{~cm}^{-1}$ coming from $\mathrm{C}=\mathrm{C}$ and $\mathrm{C}=\mathrm{O}$ stretching frequencies respectively [27]. Magnetite incorporated Poly (St-Co-MAA) (MNP@PSMA) shows the absorption peaks at $757 \mathrm{~cm}^{-1}$ and $700 \mathrm{~cm}^{-1}$ assigned to $\mathrm{C}-\mathrm{H}$ bending vibrations of mono substituted aromatic system i.e. styrene in MNP@PSMA and peaks at 1600 $-1400 \mathrm{~cm}^{-1}$ correspond to aromatic $\mathrm{C}=\mathrm{C}$ stretching frequencies. The peaks at $1452 \mathrm{~cm}^{-1}, 906 \mathrm{~cm}^{-1}$ reveal about $\mathrm{O}-\mathrm{H}$ bending frequencies of methacrylic acid (MAA). Coupling of bovine serum albumin (BSA) onto surface of composite magnetic supports was confirmed by the characteristic absorption bands at $1726 \mathrm{~cm}^{-}$ ${ }^{1}$ assigned to CO stretching of amide linkage resulting from condensation between surface carboxyl groups on the support and amine groups of BSA protein. Another indication of coupling in MNP@PSMA was from the absence of peak at $1540 \mathrm{~cm}^{-1}$ that comes from $\mathrm{N}-\mathrm{H}$ deformation in amide.

Powder X-ray diffraction (XRD) patterns were measured for $\mathrm{Fe}_{3} \mathrm{O}_{4}$ nanoparticles and its subsequent steps towards coupling with BSA as shown in Figur 1.
The peaks at $30^{\circ}, 35.5^{\circ}, 43.2^{\circ}, 57.3^{\circ}, 62.8^{\circ}$ correspond to pristine $\mathrm{Fe}_{3} \mathrm{O}_{4}$ nanoparticles with indices (220) (311) (400) (511) (440) respectively [28]. Upon surface functionalization, the XRD reveals a broad peak at $15^{\circ}$ which indicates that MPS has been successfully anchored onto the magnetite shell. Successful modification of MNP-MPS leads to formation of MNP@PSMA, which was confirmed by the appearance of peak at $20^{\circ}$ and a characteristic peak of the polymer, along with other peaks of MNP's at $35.5^{\circ}, 57.3^{\circ}$ and $62.8^{\circ}$. Coupling of MNP@PSMA with BSA was established by change in the crystallinity through XRD measurements.

VSM studies show (Figure 2) that the hysteresis loop of magnetic nanoparticles (MNP's) and magnetite composite particles (MNP@PSMA). Bare MNP's have shown saturation magnetization (Ms) of $70 \mathrm{emu} / \mathrm{g}$ whereas MNP@PSMA composite particles show 20 emu/g due to the formation of polymer layer around magnetite nanoparticles which tends to decrease the magnetization for MNP@PSMA [29].

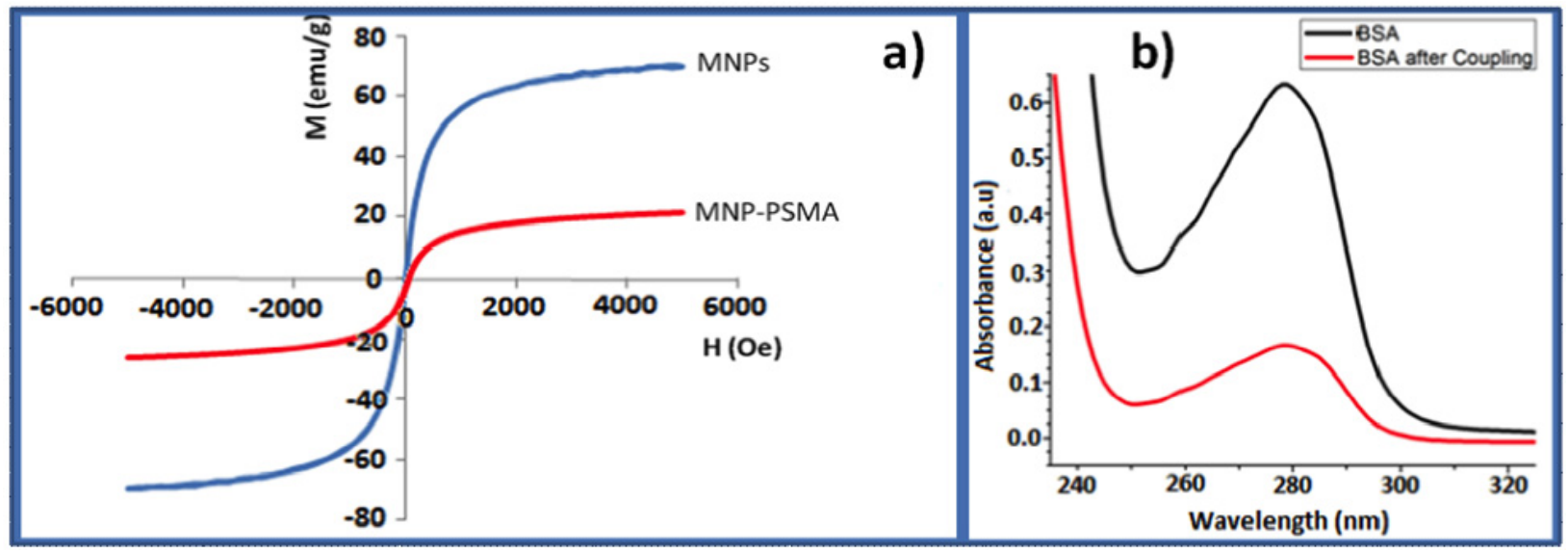

Figure 2: a) Magnetization curve of MNPs, MNP-PSMA and b) UV absorbance studies of BSA, BSA after coupling. 

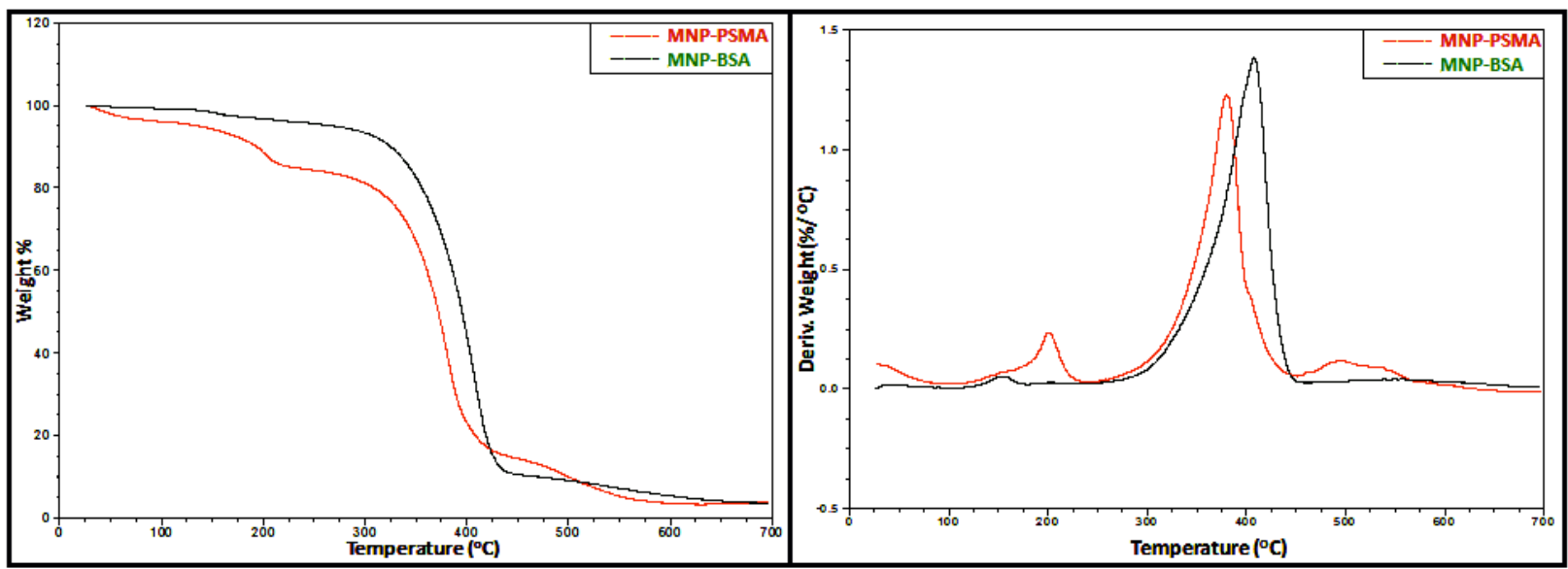

Figure 3: TGA and DTG profiles of (a) MNP@PSMA (b) BSA@MNP@PSMA.

Table 1: TGA, DTG Data of (a) MNP@PSMA (b) BSA@MNP@PSMA

\begin{tabular}{|c|c|c|c|c|c|}
\hline Sample code & $\mathrm{T}_{\mathrm{oN}}$ & $\mathrm{T}_{\mathrm{d} \max }$ & $\mathrm{T}_{\mathrm{d} 30}$ & $\mathrm{~T}_{\mathrm{d} 60}$ & \% wt. remaining at 700 \\
\hline \hline MNP@PSMA & 347.53 & 379.45 & 343.05 & 380.11 & 3.805 \\
\hline BSA@MNP@PSMA & 364.98 & 407.90 & 372.83 & 402.61 & 3.551 \\
\hline
\end{tabular}

Where $T_{\mathrm{ON}}=$ Onset decomposition temperature, $\mathrm{T}_{\mathrm{d} \max }=$ Maximum decomposition temperature, $\mathrm{T}_{\mathrm{d} 30}=30 \%$ weight decomposition temperature, $\mathrm{T}_{\mathrm{d} 60}=60 \%$ weight decomposition temperature.

Thermo gravimetric analysis (TGA) was used to determine the weight percent of nanoparticles present in the copolymer. Residual percentage of weights at $700^{\circ} \mathrm{C}$ were $3.805 \%, 3.551 \%$ corresponding to MNP@PSMA and BSA@MNP@PSMA respectively. Degradation profiles of MNP@PSMA and BSA@MNP@PSMA were shown in Figure 3. Compared to MNP@PSMA, the stability for protein coupled polymer nanocomposite (BSA@MNP@PSMA) was high due to coupling of BSA onto MNP@PSMA surface [30]. The onset decomposition temperature and maximum decomposition temperatures for the samples were listed in Table 1.

The acid values of MNP@PSMA and BSA@MNP@PSMA are 502 and 203 mg KOH/gram respectively which means that $8.95 \mathrm{meq} / \mathrm{gram}$ of carboxyl groups are available for binding on MNP@PSMA which reduces to 3.63 meq/gram after binding with BSA for BSA@MNP@PSMA. This feature clearly indicates that the mosaic structured MNP@PSMA could accommodate more than half of the surface of the composite nanoparticle supports for effective binding of BSA protein.

From UV absorption studies, a comparison for the intensities of absorption peaks for the plain BSA and the remaining supernatant after binding on BSA@MNP@PSMA had shown that around 70\% of
BSA was coupled to MNP@PSMA nanoparticles. The experimental ratio of MNP@PSMA and BSA for coupling reaction was $1: 0.5$ grams. From the UV data quantification of BSA coupled with MNP@PSMA support nanoparticles was found to be $350 \mathrm{mg} / \mathrm{gram}$. UV spectra's for plain BSA and remaining BSA in the supernatant after coupling withMNP@PSMA were shown in Figure 2.

TEM images for the morphology and size of support MNP's are shown in Figure 4. The nanoparticles displayed a uniform and narrow size distribution with an average diameter of 30-35 nm and a mosaic type of external morphology. Selected area electron diffraction (SAED pattern of the magnetic nanoparticles represents the polycrystalline nature of the MNP's present on the polymer support nanoparticles.

Protein separation studies were performed by applying external magnetic field. Magnetic behavior of MNPs, MNP@PSMA, BSA@MNP@PSMA with external magnetic field were shown in Figure 5.

\section{CONCLUSIONS}

Results presented reveal that synthesis of nanosized magnetic polymer supports with large surface area that can accommodate functionality necessary for effective coupling with biological entities 

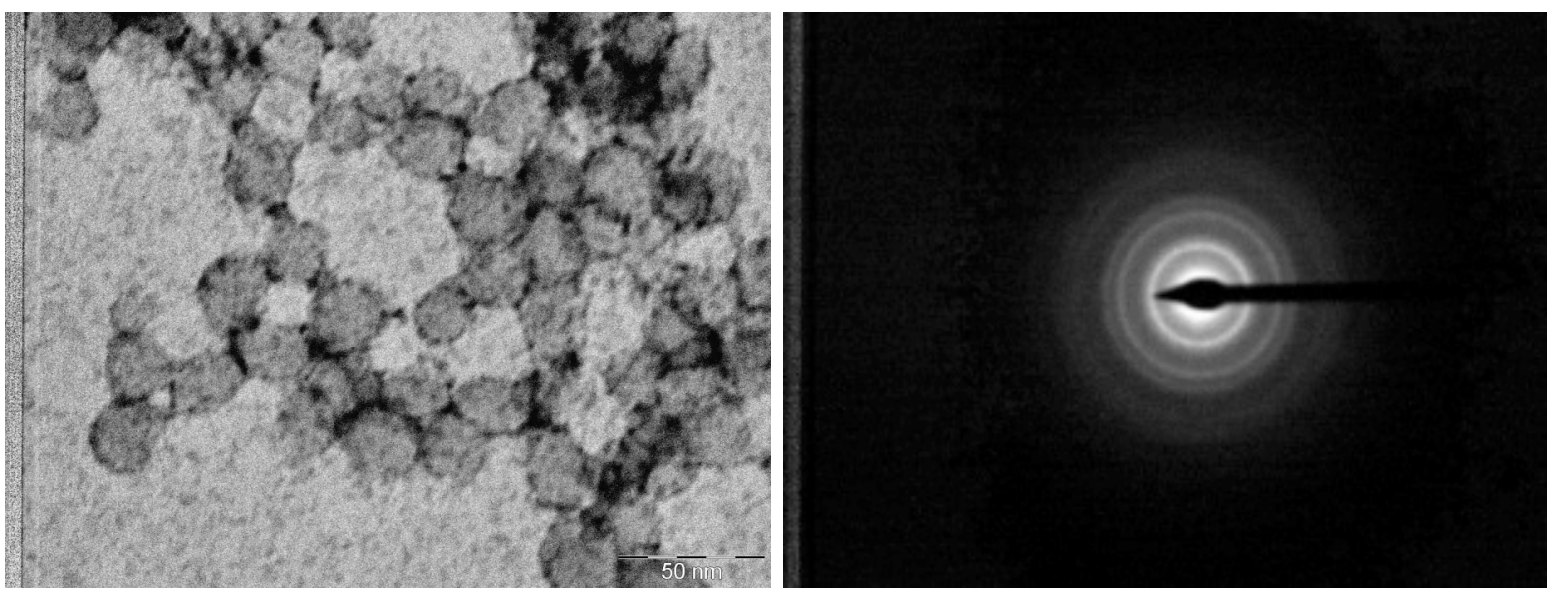

Figure 4: TEM and SAED images of BSA@MNP@PSMA.

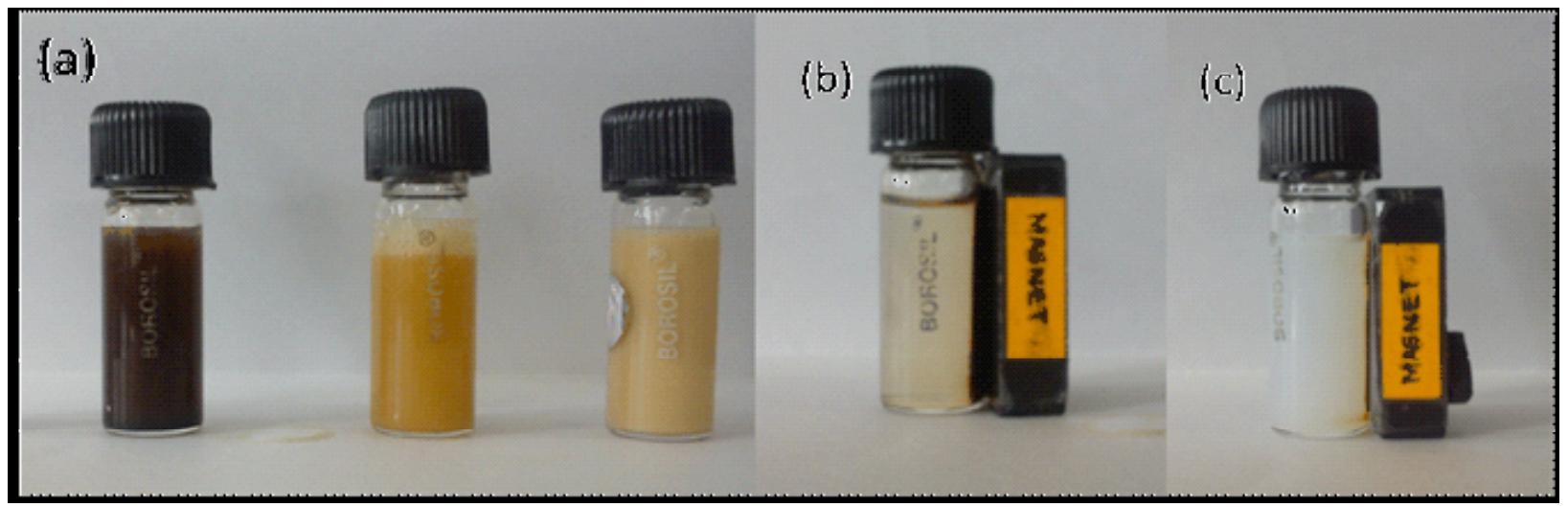

Figure 5: Digital photographs of magnetic separation of (a) MNP's, MNP@PSMA, BSA@MNP@PSMA (b) MNP's and (c) BSA@MNP@PSMA in the presence of external magnetic field.

giving high saturation magnetization is essential in the field of Biomedicine. Microemulsion method yielded in spherical composite nanoparticles (<50 nm) with mosaic decoration of MNP's on them as observed in TEM images. The possibility to accommodate maximum MNP's on the BSA@MNP@PSMA nanoparticles gave saturation magnetization of 20.0 emu/g which enables quick separation in the presence of external magnetic field. Such magnetic polymer supports $(30-50 \mathrm{~nm})$ having dimensions smaller than or comparable to that of proteins $(5-50 \mathrm{~nm})$ can exhibit close interaction for effective protein separation.

\section{ACKNOWLEDGEMENT}

Mr. Kesavarao Sykam would like to express his gratitude to University Grants Commission (UGC), India, for the research fellowship.

\section{REFERENCES}

[1] Pankhurst Q, Connolly J, Jones S, Dobson J. Applications of magnetic nanoparticles in biomedicine. J Phys D: Appl Phys 2003; 36: 167-81.

http://dx.doi.org/10.1088/0022-3727/36/13/201
[2] Zhang F, Jun J, Xing Z, et al. Pd immobilized on aminefunctionalized magnetite nanoparticles: a novel and highly active catalyst for hydrogenation and Heck reactions. Green Chemistry 2011; 5: 1238-43. http://dx.doi.org/10.1039/c0gc00854k

[3] Ranjbakhsh E, Bordbar AK, Abbasi M, Khosropour AR, Shams E. Enhancement of stability and catalytic activity of immobilized lipase on silica-coated modified magnetite nanoparticles. Chemical Engineering Journal 2012; 179: 2726 http://dx.doi.org/10.1016/j.cej.2011.10.097

[4] Zhang $Y$, Sichao X, Yuanyuan L, et al. Synthesis of mesoporous carbon capsules encapsulated with magnetite nanoparticles and their application in wastewater treatment. Journal of Materials Chemistry 2011; 11: 3664-71. http://dx.doi.org/10.1039/c0jm03727c

[5] Piao X, Guang MZ, Dan LH, et al. Use of iron oxide nanomaterials in wastewater treatment: a review. Science of the Total Environment 2012; 424: 1-10.

http://dx.doi.org/10.1016/j.scitotenv.2012.02.023

[6] Tartaj P, Morales M, Veintemillas VS, Gonzalez CT, Serna C. The preparation of magnetic nanoparticles for applications in biomedicine. J Phys D: Appl Phys 2003; 36: 182-97. http://dx.doi.org/10.1088/0022-3727/36/13/202

[7] Liu G, Zhiyong W, Jian L, et al. Low molecular weight alkylpolycation wrapped magnetite nanoparticle clusters as MRI probes for stem cell labelling and in vivo imaging. Biomaterials 2011; 32: 528-37.

http://dx.doi.org/10.1016/j.biomaterials.2010.08.099 
[8] Lee JH, Huh $\mathrm{YM}$, Jun $\mathrm{Y}$, et al. Artificially engineered magnetic nanoparticles for ultra-sensitive molecular imaging. J Nat Med 2007; 13: 95-9. http://dx.doi.org/10.1038/nm1467

[9] Schmieder AH, Winter PM, Caruthers SD, et al. Molecular MR imaging of melanoma angiogenesis with anb3-targeted paramagnetic nanoparticles. Magn Reson Med 2005; 53: 621-7.

http://dx.doi.org/10.1002/mrm.20391

[10] Nakamae K, Tanigawa S, Tsujiguchi T, Okamoto S, Yamaguchi K. Solvent effect on adsorption of polymers on $y$ $\mathrm{Fe}_{2} \mathrm{O}_{3}$ particles. Coll Surf A 1993; 80-5.

[11] Liu X, Guan Z, Liu H, et al. Preparation and characterization of magnetic polymer nanospheres with high protein binding capacity. J Magn Magn Mater 2005; 293: 111-8. http://dx.doi.org/10.1016/j.jmmm.2005.01.051

[12] Harris LA, Goff JD, Carmichael AZ, et al. Magnetite nanoparticle dispersions stabilized with triblock copolymers. Chem Mater 2003; 15: 1367-77. http://dx.doi.org/10.1021/cm020994n

[13] Alexiou C, Arnold W, Hulin P, et al. Magnetic mitoxantrone nanoparticle detection by histology, X-ray and MRI after magnetic tumor targeting. J Magn Magn Mater 2001; 225: 187-93.

http://dx.doi.org/10.1016/S0304-8853(00)01256-7

[14] Bergemann C, Miiller SD, Oster J, Brassard L, Ans L. Magnetic ion-exchange nano-and microparticles for medical, biochemical and molecular biological applications. J Magn Magn Mater 1999; 194: 45-54. http://dx.doi.org/10.1016/S0304-8853(98)00554-X

[15] Goetze T, Gansau C, Buske N, et al. Photoacoustic spectroscopy of magnetic fluids. J Magn Magn Mater 2002; 252: $56-58$.

http://dx.doi.org/10.1016/S0304-8853(02)00685-6

[16] Hyeon T, Lee SS, Park J, Chung Y, Na HB. Synthesis of highly crystalline and monodisperse maghemite nanocrystallites without a size-selection process. J Am Chem Soc 2001; 123: 12798-801.

http://dx.doi.org/10.1021/ja016812s

[17] Suslick KS, Fang M, Hyeon T. Sonochemical Synthesis of Iron Colloids. J Am Chem Soc 1996; 118: 11960-1. http://dx.doi.org/10.1021/ja961807n

[18] Xu Z, Liu Q, Finch JA. Silanation and stability of 3aminopropyl triethoxysilane on nanosized super paramagnetic particles. Appl Surf Scl 1997; 120: 269-78. http://dx.doi.org/10.1016/S0169-4332(97)00234-1

[19] Donselaar LN, Philipse AP, Suurmond J. Concentrationdependent sedimentation of dilute magnetic fluids and magnetic silica dispersions. Langmuir 1997; 13: 6018-25. http://dx.doi.org/10.1021/la970359+
[20] Liu Q, Xu Z, Finch JA, Egerton R. A novel two-step silicacoating process for engineering magnetic nanocomposites. Chem Mater 1998; 10: 3936-40. http://dx.doi.org/10.1021/cm980370a

[21] Klotz M, Ayral A, Guizard C, Menager C, Cabuil V. Silica coating on colloidal maghemite particles. J Coll Int Sci 1999; 220: 357-61.

http://dx.doi.org/10.1006/jcis.1999.6517

[22] Lu Y, Yin Y, Mayers BT, Xia Y. Modifying the surface properties of super paramagnetic iron oxide nanoparticles through a sol-gel approach. Nano Lett 2002; 2: 183-6. http://dx.doi.org/10.1021/nl015681q

[23] Seip CT, O'Connor CJ. Synthesis and reactivity of nanophase ferrites in reverse micellar solutions. Nanostruct Mater 1999; 12: 183-6. http://dx.doi.org/10.1016/S0965-9773(99)00094-X

[24] Cho SJ, Kauzlarich SM, Olamit J, et al. Characterization and magnetic properties of core/shell structured $\mathrm{Fe} / \mathrm{Au}$ nanoparticles. J Appl Phys 2004; 95: 6804-06.

http://dx.doi.org/10.1063/1.1676033

[25] Chen M, Yamamuro S, Farrell D, Majetich SA. Gold-coated iron nanoparticles for biomedical applications. Appl Phys 2003; 93: 7551-3. http://dx.doi.org/10.1063/1.1555312

[26] Pei L, Jianjun X, Qun W, Chi W. Surface functionalization of polymer latex particles: 4. Tailor-making of aldehydefunctional poly (methylstyrene) latexes in an emulsifier-free system. Langmuir 2000; 16: 4141-7. http://dx.doi.org/10.1021/la9912949

[27] Liua ZL, Dinga ZH, Yaoa KL, et al. Preparation and characterization of polymer-coated core-shell structured magnetic microbeads. J Magn Magn Mater 2003; 265: 98105.

http://dx.doi.org/10.1016/S0304-8853(03)00230-0

[28] Elizabeth RB, Iva P, Ana MF, Helena SA, Rui LR. Synthesis and functionalization of super paramagnetic poly- $\varepsilon$ caprolactone microparticles for the selective isolation of sub populations of human adipose-derived stem cells. J R Soc Interface 2011; 8: 896-908. http://dx.doi.org/10.1098/rsif.2010.0531

[29] Ruixue L, Shumei L, Jianqing Z, Hideyuki O, Atsushi T. Preparation of super paramagnetic b-cyclodextrin functionalized composite nanoparticles with core-shell structures. Polym Bull 2011; 66: 1125-36. http://dx.doi.org/10.1007/s00289-010-0410-y

[30] Dong GL, Kanagasabai MP, Mir K, et al. Immobilization of lipase on hydrophobic nano-sized magnetite particles. J Mol Catal B: Enzym 2009; 57: 62-6. http://dx.doi.org/10.1016/j.molcatb.2008.06.017 